\title{
West Highland White Terrier
}

National Cancer Institute

\section{Source}

National Cancer Institute. West Highland White Terrier. NCI Thesaurus. Code C53739.

The West Highland White Terrier is a sturdy, hardy, compact little terrier with a two inch, all-white coat that is uncurled with a soft, dense undercoat. The ears are small, pointed and erect. Height: 9-12 inches (23-30 cm.) Weight: 13-22 pounds (6-10 kg.) 